\title{
Academic Pre-Orientation Program for Dental Students: Beginning and End of Program Evaluations, 1998-2016
}

\author{
Evan R. D'Silva, BA; Marilyn W. Woolfolk, DDS, MPH; Renee E. Duff, DDS, MS; \\ Marita R. Inglehart, Dr phil habil
}

Abstract: Admitting students from non-traditional or disadvantaged backgrounds can increase the diversity of dental school classes. The aims of this study were to analyze how interested non-traditional incoming dental students were at the beginning of an academic pre-orientation program in learning about basic science, dentistry-related topics, and academic skills; how confident they were in doing well in basic science and dentistry-related courses; and how they evaluated the program at the end. The relationships between personal (interest/confidence) and structural factors (program year, number of participants) and program evaluations were also explored. All 360 students in this program at the University of Michigan from 1998 to 2016 were invited to participate in surveys at the beginning and end of the educational intervention. A total of 353 students responded at the beginning (response rate 98\%), and 338 responded at the end (response rate 94\%). At the beginning, students were more interested in learning about basic science and dentistry-related topics than about academic skills, and they were more confident in their dentistryrelated than basic science-related abilities. At the end, students valued basic science and dentistry-related education more positively than academic skills training. Confidence in doing well and interest in basic science and dentistry-related topics were correlated. The more recent the program was, the less confident the students were in their basic science abilities and the more worthwhile they considered the program to be. The more participants the program had, the more confident the students were, and the better they evaluated their basic science and dentistry-related education. Overall, this academic pre-orientation program was positively evaluated by the participants.

\begin{abstract}
Mr. D'Silva is Research Assistant, Department of Periodontics and Oral Medicine, School of Dentistry, University of Michigan; Dr. Woolfolk is Emerita Professor, Department of Periodontics and Oral Medicine and Assistant Dean Emerita, School of Dentistry, University of Michigan; Dr. Duff is Clinical Associate Professor, Department of Biologic and Materials Sciences and Assistant Dean for Student Services, School of Dentistry, University of Michigan; and Dr. Inglehart is Professor, Department of Periodontics and Oral Medicine, School of Dentistry and Adjunct Professor, Department of Psychology, College of Literature, Science, \& Arts, University of Michigan. Direct correspondence to Dr. Marita R. Inglehart, Department of Periodontics and Oral Medicine, School of Dentistry, University of Michigan, 1011 N. University Street, Ann Arbor, MI 48109-1078; 734-763-8073; mri@umich.edu.
\end{abstract}

Keywords: dental education, dental students, orientation, program evaluation, cultural diversity, basic science, academic skills

Submitted for publication 5/26/17; accepted 10/23/17

doi: 10.21815/JDE.018.039

$\mathrm{O}$ ver a century ago, Abraham Flexner wrote his famous report about medical education in which he emphasized that the biomedical sciences were the core of medical education and called for "fewer and better doctors." His emphasis crucially affected admissions policies of medical schools and the types of students medical school admissions officers targeted. ${ }^{2,3}$ Calls for transforming admission policies by going beyond the consideration of traditional academic indicators such as MCAT scores and grade point averages has since then become central to the discussion of admission policies. $^{4,5}$

These considerations of applying a more holistic approach to the selection of students for health professions education have not only affected medical school admissions policies, ${ }^{6,7}$ but have also been discussed in nursing education and dental education. ${ }^{8,9}$ The ultimate goal of these efforts is to select future health care providers who will provide the best possible care to an increasingly diverse patient population in the U.S. Recruiting students from diverse ethnic/racial groups and socioeconomic backgrounds as well as students who have core personal competencies such as a positive service orientation, ethical responsibility to self and others, social skills, cultural competence, and the ability to work in teams has become a central goal in admission policies and processes. ${ }^{2,10,11}$

While there is no doubt that diversity in higher education has a positive effect on academic outcomes in general, ${ }^{12}$ one crucial question is how to ensure that 
students from non-traditional backgrounds - such as health professions students with college majors in the humanities or social sciences or with years of employment between college graduation and professional school enrollment-receive the support they may need to adjust to the stringent curricula of health professions schools. In 1994, the University of Michigan School of Dentistry began to address this concern by developing an academic pre-orientation program for non-traditional or disadvantaged predoctoral dental students. The aims of this study were to analyze how interested non-traditional incoming dental students were at the beginning of this program in learning about basic science, dentistry-related topics, and academic skills; how confident they were in doing well in basic science and dentistry-related courses; and how they evaluated the program at the end. The relationships between personal (interest/ confidence) and structural factors (program year, number of participants) and program evaluations were also explored.

\section{Methods}

This study was determined to be exempt from oversight by the Institutional Review Board for the Health and Behavioral Sciences at the University of Michigan on January 17, 2014 (HUM\#00084729). Between 1998 and 2016, approximately 105 students began study in the dental school each year. A total of 460 of these students were invited to an academic pre-orientation session because they came from nontraditional or disadvantaged backgrounds. Race could not be considered since 2006 when a ballot initiative ("Proposal 2") was passed, and the Michigan constitution was amended to make it illegal for state entities to consider race in university/college admissions or other decisions (see ballotpedia.org/Michigan_Civil_ Rights_Amendment_Proposal_2_2006). Examples of non-traditional backgrounds were non-basic science majors such as art or philosophy and having had a number of gap years between graduating from college and entering the dental school. Examples of students from disadvantaged backgrounds were students from small colleges or students who were the first in their families to attend college. Among the invited students, 100 declined to participate in the program, and 360 participated between 1998 and 2016 (Table 1). The number of participants per year ranged from seven to 28 (mean=20.34; $\mathrm{SD}=4.65$ ). For students in the 1998, 2000, and 2002-13 programs, group-based demographic information (gender, age, ethnicity/race, and citizenship and residency status) was available from the school's student affairs office. However, for 1999 and 2001, participant names could not be identified.

From 1998 to 2011, the program took place in the two weeks before the beginning of the first year of dental school (D1); from 2012 to 2016, the program occurred in the week prior to the official start of the D1 year. Each year, the program began on a Monday morning with a pre-orientation breakfast during which the students received a paper and pencil

Table 1. Overview of students in program 1998-2016 and their demographic information

\begin{tabular}{lc} 
Program/Study Characteristic & Data \\
\hline Years included & 1998 to $2016(\mathrm{~N}=19)$ \\
Respondents & \\
Beginning surveys & 353 (response rate: $98 \%)$ \\
End surveys & 338 (response rate: $94 \%)$ \\
Participants per year & \\
Mean (SD; range) & $20.34(4.65 ; 7$ to 28$)$ \\
Students in & \\
2-week program (1994-2011) & $279(78 \%)$ \\
1-week program (2012-16) & $81(23 \%)$
\end{tabular}

\begin{tabular}{lcc} 
Student demographics & $\begin{array}{c}\text { Participants } \\
\mathrm{N}=259\end{array}$ & $\begin{array}{c}\text { Invited But Did } \\
\text { Not Participate } \\
\mathrm{N}=100\end{array}$ \\
\hline Gender & & \\
Male & $50 \%$ & $53 \%$ \\
Female & $50 \%$ & $47 \%$
\end{tabular}

$\begin{array}{lcc}\text { Age at enrollment } & & \\ \text { Mean (SD) } & 25.28(4.02) & 25.38(3.63) \\ \text { Range } & 21-40 & 21-41\end{array}$

Ethnicity

European American $\quad 42 \% \quad 54 \%$

African American $\quad 29 \% \quad 6 \%$

Asian American $\quad 16 \% \quad 31 \%$

Hispanic/Latino/a $\quad 9 \% \quad 3 \%$

Other or not indicated $\quad 3 \% \quad 5 \%$

American Indian $\quad 1 \% \quad 1 \%$

$\begin{array}{ll}\text { U.S. citizen: Yes } \quad 94 \% & 90 \%\end{array}$

Residency

In-state $\quad 46 \% \quad 45 \%$

Out-of-state $\quad 50 \% \quad 50 \%$

Not known $\quad 4 \% \quad 5 \%$

Note: Demographic information is for students in program years 1998, 2000, and 2002-13. No demographic data were available for students in 1999 and 2001 because students' names were no longer available and for students in the three most recent years (2014-16) because not all students responded to the anonymous surveys. 
survey. They responded to this survey and handed it back anonymously at the end of the breakfast. At the end of the last day of the pre-orientation program, paper and pencil surveys were again distributed to the students; they returned their responses anonymously. So that students' beginning and end responses could be matched, they were asked to add their mother's birthdate to both surveys.

The objectives of the program were to provide introductions to the upcoming basic science courses, preclinical activities, and dental-related content. In addition, an academic skills section focused on increasing students' understanding of how to develop a study skill approach best suited to learning in dental school, and organizational information about financial aid, personal services, the dental school, and the surrounding town was shared with the students. The design of the program changed over time with changes in the academic offerings. For example, between 1998 and 2009, discipline-specific basic science courses were offered in the D1 year, so the preparation for these courses was also disciplinespecific. However, starting in 2010, the curriculum changed to a system-based approach that integrated basic and dental science content and organized it by bodily system. The participants in all years had a chance to experience preclinical lab activities and were introduced to dental-related content.

Table 2 provides an overview of the content covered in the program from 1998 to 2016, based on four content blocks: basic science, dentistryrelated, academic skills, and organizational content. The early years from 1998 to 2009 included basic science-related content: biochemistry, microbiology, immunology, and histology. In 2010 and 2011, the dental school went to an integrated basic science curriculum, and the program accounted for this change by presenting basic science in a more integrated fashion in 2013-16. Two interactive sessions in head and neck anatomy were included. Also,

\begin{tabular}{|c|c|c|c|}
\hline Program Component & 1998-2009 & 2010-12 & 2013-16 \\
\hline \multicolumn{4}{|l|}{ Basic science content } \\
\hline Biochemistry & Yes & \multirow[t]{4}{*}{ Integrated } & \multirow{4}{*}{$\begin{array}{l}\text { Integrated into Head } \\
\text { and Neck Anatomy }\end{array}$} \\
\hline Microbiology & Yes & & \\
\hline Immunology & Yes & & \\
\hline Histology & Yes & & \\
\hline Basic science index $(\mathrm{N}=240)$ & Yes & \multicolumn{2}{|c|}{ No basic science specific evaluation data available } \\
\hline \multicolumn{4}{|l|}{ Dental-related content } \\
\hline Dental anatomy & Yes & Yes & \multirow[t]{3}{*}{ Head and Neck Anatomy } \\
\hline Biology of dentition & Yes & No & \\
\hline Dental materials & Yes & No & \\
\hline Preclinical skills & Yes & Yes & Yes \\
\hline Dental content index $(\mathrm{N}=241)$ & Yes & No & Yes \\
\hline \multicolumn{4}{|l|}{ Getting to know } \\
\hline Dental clinics $(\mathrm{N}=55)$ & No & No & 2014-16 \\
\hline Dental instructors $(\mathrm{N}=349)$ & Yes & Yes & Yes \\
\hline Dental students $(\mathrm{N}=111)$ & No & Yes & Yes \\
\hline \multicolumn{4}{|l|}{ Academic skills content } \\
\hline Reading skills & Yes & Yes & Yes \\
\hline Test taking skills & Yes & Yes & Yes \\
\hline Time management & Yes & Yes & Yes \\
\hline Stress and coping & Yes & Yes & Yes \\
\hline Academic skill index $(\mathrm{N}=343)$ & Yes & Yes & Yes \\
\hline \multicolumn{4}{|l|}{ Organizational skills content } \\
\hline Financial aid & Yes & Yes & Yes \\
\hline Tour of Ann Arbor & Yes & Yes & No questions asked \\
\hline Personal services & Yes & Yes & \\
\hline Find way around dental school & Yes & Yes & \\
\hline Find housing & Yes & No & \\
\hline Organizational index $(\mathrm{N}=194)$ & Yes & No & No \\
\hline
\end{tabular}


specific course-related case studies in oral pathology and oral medicine were developed with the help of course directors and were presented in the academic skills sessions to specifically address strategies for managing the basic science curriculum. From 2012 to 2016 , the program went from two weeks to one week. This time reduction resulted in decreased coverage of basic science-related content.

Students were also informed about upcoming classes with dental-related content, specifically dental anatomy and preclinical skills courses, and received academic skills training in the form of workshops on reading skills, test taking skills, time management, and stress and coping. All students received information about financial aid; and from 1998 to 2011 and in 2013 and 2016, information about Ann Arbor, the dental school building, and other organizational matters were also addressed. Presentations by dental school instructors about upcoming course content and social events with dental students complemented the academic content. In addition, information about navigating Ann Arbor and community resources were presented in student panels, a campus tour, and sessions with the assistant dean for student services.

The beginning-of-program survey consisted of a general question inquiring how interested the students were about participating in the program overall. Between 1998 and 2009, one section of questions asked how interested the students were in reviewing/learning about certain basic sciencerelated topics (biochemistry, microbiology, immunology, and histology). All students answered questions concerning how interested they were in learning about dental anatomy and preclinical skills and getting to know instructors and other dental students. A second section asked about their confidence in doing well in upcoming academic courses. A third section inquired if it was useful to cover skills related to their academic achievement such as reading, test taking, and time and stress management.

The end-of-program survey also began with a general question asking whether students' participation in the program had been worth their time. This question was answered on a five-point scale from $1=$ not at all worthwhile to $5=$ very worthwhile. The survey also asked how helpful it was to review/ learn about academic subjects, academic skills, and organizational matters prior to the first day of dental school. All answers to those questions were given on a four-point scale from $1=$ not at all to $4=$ most positive response.
The survey data were entered into SPSS, Version 22.0 (IBM Corp., Armonk, NY, USA). Descriptive statistics such as frequency distributions, percentages, means, standard deviations, and ranges were computed to provide an overview of the responses. Pearson correlation coefficients were used to determine the relationships between the indices at the beginning and end and the number of participants in the program and the year of the program. A significance level of $\mathrm{p}<0.05$ was used to determine the level of significance.

\section{Results}

A total of 353 students responded to surveys at the beginning of the program (response rate 98\%), and 338 responded to the end-of-program surveys (response rate 94\%). In 1998, 2000, and 2002 to 2013, about half of the participants were male and half were female, and participants ranged in age from 21 to 40 years (mean age $=25.28, \mathrm{SD}=4.02$ ) (Table 1). Race/ ethnicity of $42 \%$ of the participants was EuropeanAmerican, with 29\% African American, 16\% Asian American, 9\% Hispanic-Latino, and 1\% American Indian. Nearly all (94\%) were U.S. citizens; $46 \%$ were from Michigan, $50 \%$ were from out-of-state, and $4 \%$ did not report residency status. When we compared the characteristics of program participants with the 100 students who were invited but did not participate, the data showed that a higher percentage of European-American and Asian American students did not attend compared to a lower percentage of African American students.

At the beginning of the program, $81 \%$ of the students were very interested in participating, and $19 \%$ were interested (Table 3). Over $90 \%$ of the participants were interested/very interested in basic science-related content; $99 \%$ were interested/very interested in dental-related content, and $100 \%$ in getting to know the dental school, instructors, and students. A dependent sample t-test was used to compare the average interest in basic science-related content with the average interest in dental-related content. The results showed that the average interest in learning about dental-related content was significantly higher $(p<0.05)$ than the average interest in basic science.

At the beginning of the program, the students also indicated how confident they were in doing well in basic science-related content and in dental-related subjects. The average confidence levels were positive 


\section{Table 3. Overview of survey responses at beginning of program}

\begin{tabular}{|c|c|c|c|c|c|c|}
\hline Item & \# Years (N) & $1=$ Not at All & 2 & 3 & $4=$ Very Much & Mean \\
\hline \multicolumn{7}{|l|}{ I am very interested in: } \\
\hline Participating in program & $19(322)$ & 0 & 0 & $19 \%$ & $81 \%$ & 3.81 \\
\hline \multicolumn{2}{|c|}{ Reviewing/learning about basic science } & $\begin{array}{l}\text { 1=Disagree } \\
\text { Strongly }\end{array}$ & $2=$ Disagree & $3=$ Agree & $\begin{array}{l}4=\text { Agree } \\
\text { Strongly }\end{array}$ & \\
\hline Biochemistry & $12(240)$ & $2 \%$ & $6 \%$ & $34 \%$ & $59 \%$ & 3.49 \\
\hline Microbiology & $12(241)$ & $1 \%$ & $5 \%$ & $33 \%$ & $61 \%$ & 3.55 \\
\hline Immunology & $12(241)$ & 0 & $2 \%$ & $27 \%$ & $70 \%$ & 3.67 \\
\hline Histology & $12(242)$ & 0 & $2 \%$ & $26 \%$ & $72 \%$ & 3.70 \\
\hline $\begin{array}{l}\text { Beginning basic science } \\
\text { interest index }{ }^{\mathrm{a}}(\mathrm{alpha}=0.827)\end{array}$ & $12(240)$ & & Range 1. & $0-4.00$ & SD 0.48 & 3.60 \\
\hline \multicolumn{7}{|c|}{ Reviewing/learning about dental issues } \\
\hline Dental anatomy & $19(353)$ & 0 & $1 \%$ & $15 \%$ & $84 \%$ & 3.82 \\
\hline Biology of the dentition & $12(241)$ & $1 \%$ & 0 & $15 \%$ & $84 \%$ & 3.82 \\
\hline Dental materials & $12(242)$ & $1 \%$ & 0 & $22 \%$ & $77 \%$ & 3.75 \\
\hline Preclinical skills & $19(353)$ & $1 \%$ & 0 & $16 \%$ & $84 \%$ & 3.82 \\
\hline $\begin{array}{l}\text { Beginning dental interest } \\
\text { index }^{\mathrm{b}}(\mathrm{alph} a=0.877)\end{array}$ & $12(241)$ & & Range 1. & $0-4.00$ & SD 0.41 & $3.79 *$ \\
\hline \multicolumn{2}{|l|}{ It is useful to cover } & Yes & No & & & \\
\hline Reading skills & $19(346)$ & $68 \%$ & $32 \%$ & & & \\
\hline Test taking skills & $19(348)$ & $90 \%$ & $10 \%$ & & & \\
\hline Time management & $19(349)$ & $88 \%$ & $12 \%$ & & & \\
\hline Stress management & $19(349)$ & $79 \%$ & $21 \%$ & & & \\
\hline $\begin{array}{l}\text { Beginning academic skill } \\
\text { interest sum score }\end{array}$ & $19(343)$ & & & Range $0-4$ & SD 0.92 & 3.25 \\
\hline \multirow{2}{*}{\multicolumn{2}{|c|}{ I am very interested in getting to know }} & $1=$ Disagree & & & 4=Agree & \\
\hline & & Strongly & $2=$ Disagree & $3=$ Agree & Strongly & \\
\hline Dental clinics & $3(55)$ & 0 & 0 & $7 \%$ & $93 \%$ & 3.93 \\
\hline Dental instructors & $19(353)$ & 0 & 0 & $10 \%$ & $90 \%$ & 3.90 \\
\hline Dental students & $7(111)$ & 0 & 0 & $8 \%$ & $92 \%$ & 3.92 \\
\hline \multicolumn{7}{|c|}{ I am confident about doing well in basic science } \\
\hline Biochemistry & $12(238)$ & $1 \%$ & $10 \%$ & $60 \%$ & $30 \%$ & 3.18 \\
\hline Microbiology & $12(240)$ & $1 \%$ & $8 \%$ & $56 \%$ & $35 \%$ & 3.26 \\
\hline Immunology & $12(240)$ & $1 \%$ & $8 \%$ & $61 \%$ & $30 \%$ & 3.20 \\
\hline Histology & $12(238)$ & 0 & $10 \%$ & $65 \%$ & $25 \%$ & 3.14 \\
\hline $\begin{array}{l}\text { Beginning basic science } \\
\text { confidence index }^{\mathrm{d}}(\alpha=0.870)\end{array}$ & $12(237)$ & & Range 1. & $0-4.00$ & SD 0.52 & Mean 3.20 \\
\hline \multicolumn{7}{|c|}{ I am confident about doing well in dental-related topics } \\
\hline Dental anatomy & $18(322)$ & 0 & $4 \%$ & $48 \%$ & $48 \%$ & 3.43 \\
\hline Biology of the dentition & $12(239)$ & 0 & $7 \%$ & $52 \%$ & $41 \%$ & 3.35 \\
\hline Dental materials & $12(240)$ & 0 & $6 \%$ & $50 \%$ & $44 \%$ & 3.37 \\
\hline Preclinical skills & $18(322)$ & 0 & $4 \%$ & $48 \%$ & $48 \%$ & 3.45 \\
\hline $\begin{array}{l}\text { Beginning dental-related } \\
\text { confidence index }(\alpha=0.928)\end{array}$ & $12(237)$ & & Range 1 & $5-4.00$ & SD 0.54 & $3.41 * *$ \\
\hline
\end{tabular}

aThe "Beginning Basic Science Interest Index" was computed by averaging responses to the four basic science interest items.

'The "Beginning Dental Interest Index" was computed by averaging responses to the four dental content interest items.

"The "Academic Skill Interest" sum score was computed by adding one point for each "yes" response to the four academic skills items.

'The "Beginning Basic Science Confidence Index" was computed by averaging responses to the four basic science items.

eThe "Beginning Dental-Related Confidence Index" was computed by averaging responses to the four dental-related confidence ratings.

*Mean "Beginning Basic Science Interest Index" and mean "Beginning Dental Interest Index" were significantly different (dependent sample t-test: $t=5.214$; d.f. $=238 ; \mathrm{p}<0.001$ ).

** Mean "Beginning Basic Science Confidence Index" and mean "Beginning Dental-Related Confidence Index" were significantly different (dependent sample t-test: $t=56.615 ;$ d.f. $=234 ; p<0.001$ ). 
for both sets of items (Table 3 ). On a scale from $1=$ not at all to $4=$ very confident, all mean responses were higher than 3.13. However, a dependent sample t-test showed that the students' average dental-related confidence was significantly higher than their average basic science-related confidence $(\mathrm{p}<0.01)$. Most of the students found it useful to cover reading skills (68\%), test taking skills (91\%), time management skills (89\%), and stress/coping (79\%).
At the end of the program, the majority of the students $(83 \%)$ said that the orientation was very much worth their time (Table 4). As to how helpful it was to review/learn about academic subjects, the majority reported that it was very helpful. When asked how helpful it was to learn about the organizational/ nonacademic subjects and to have academic skills training, the average responses for the organizational/ nonacademic subjects were more positive (on a scale

\section{Table 4. Overview of survey responses at end of program}

\begin{tabular}{|c|c|c|c|c|c|c|}
\hline Question & \# Years (N) & $1=$ Not at All & 2 & $3 / 4$ & $5=$ Very Much & Mean \\
\hline $\begin{array}{l}\text { Was this orientation worth } \\
\text { your time? }\end{array}$ & $17(290)$ & $5 \%$ & $2 \%$ & $1 \% / 9 \%$ & $83 \%$ & 4.62 \\
\hline \multicolumn{2}{|l|}{$\begin{array}{l}\text { How helpful was it to review/learn } \\
\text { about these academic subjects }{ }^{b}\end{array}$} & $1=$ Very & 2 & 3 & 4=Not at All & \\
\hline Biochemistry & $8(160)$ & $57 \%$ & $27 \%$ & $9 \%$ & $6 \%$ & 1.64 \\
\hline Microbiology & $10(160)$ & $54 \%$ & $33 \%$ & $4 \%$ & $9 \%$ & 1.68 \\
\hline Immunology & $9(183)$ & $53 \%$ & $34 \%$ & $10 \%$ & $3 \%$ & 1.63 \\
\hline Histology & $9(177)$ & $57 \%$ & $31 \%$ & $4 \%$ & $8 \%$ & 1.63 \\
\hline $\begin{array}{l}\text { End basic science evaluation } \\
\text { index }^{c}(\text { alpha }=0.948)\end{array}$ & $6(138)$ & & \multicolumn{2}{|c|}{ Range 1.00-4:00 } & SD 0.86 & 1.70 \\
\hline Preclinical skills & $17(302)$ & $75 \%$ & $17 \%$ & $2 \%$ & $6 \%$ & 1.39 \\
\hline Biology of the dentition & $6(136)$ & $49 \%$ & $29 \%$ & $16 \%$ & $7 \%$ & 1.80 \\
\hline Dental anatomy & $15(272)$ & $76 \%$ & $17 \%$ & $4 \%$ & $4 \%$ & 1.35 \\
\hline Dental materials & $12(235)$ & $64 \%$ & $25 \%$ & $6 \%$ & $4 \%$ & 1.51 \\
\hline $\begin{array}{l}\text { End dental topic evaluation } \\
\text { index }^{d}(\text { alpha }=0.911)\end{array}$ & $6(138)$ & & Rang & $-4: 00$ & SD 0.82 & 1.71 \\
\hline \multicolumn{7}{|c|}{ How helpful was it to learn about these academic skills } \\
\hline Reading skills & $11(217)$ & $15 \%$ & $45 \%$ & $32 \%$ & $7 \%$ & 2.31 \\
\hline Time management & $14(268)$ & $35 \%$ & $42 \%$ & $18 \%$ & $5 \%$ & 1.94 \\
\hline Stress management & $14(258)$ & $31 \%$ & $43 \%$ & $20 \%$ & $7 \%$ & 2.03 \\
\hline Test taking skills & $14(267)$ & $25 \%$ & $45 \%$ & $25 \%$ & $5 \%$ & 2.09 \\
\hline $\begin{array}{l}\text { End evaluation of academic } \\
\text { skills education }^{\mathrm{e}}(\text { alpha }=0.912)\end{array}$ & $10(203)$ & & Rang & -4.00 & SD 0.77 & 2.18 \\
\hline \multicolumn{7}{|l|}{ How helpful was it to } \\
\hline $\begin{array}{l}\text { Find your way around } \\
\text { Ann Arbor? }\end{array}$ & $14(254)$ & $46 \%$ & $37 \%$ & $10 \%$ & $8 \%$ & 1.80 \\
\hline $\begin{array}{l}\text { Find your way around the } \\
\text { dental school? }\end{array}$ & $15(247)$ & $65 \%$ & $23 \%$ & $5 \%$ & $8 \%$ & 1.54 \\
\hline Establish personal services? & $14(255)$ & $64 \%$ & $22 \%$ & $6 \%$ & $9 \%$ & 1.60 \\
\hline Find housing? & $14(227)$ & $34 \%$ & $25 \%$ & $15 \%$ & $26 \%$ & 2.33 \\
\hline Learn about financial aid? & $17(301)$ & $56 \%$ & $30 \%$ & $6 \%$ & $8 \%$ & 1.66 \\
\hline $\begin{array}{l}\text { End organizational index }{ }^{f} \\
(\text { alpha }=0.873)\end{array}$ & $13(194)$ & & \multicolumn{2}{|c|}{ Range 1.00-4.00 } & SD 0.83 & 1.85 \\
\hline $\begin{array}{l}\text { Find your way around the } \\
\text { medical school? }\end{array}$ & $9(263)$ & $60 \%$ & $24 \%$ & $9 \%$ & $7 \%$ & 1.63 \\
\hline
\end{tabular}

Note: While the mean "End Basic Science Evaluation Index" and the mean "End Dental Topic Evaluation Index" were not significantly different (dependent sample t-test: $t=-0.370 ; d . f .=113 ; p=0.712$ ), each of these two mean indices differed significantly from the mean "End Evaluation of Academic Skills Education Index" (dependent sample t-test: $t=-9.183 ;$ d.f. $=135 ; \mathrm{p}<0.001 / \mathrm{t}=-7.185 ; \mathrm{d} . \mathrm{f} .=116$; $\mathrm{p}<0.001)$.

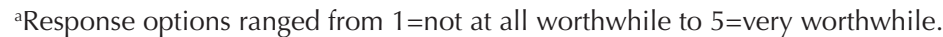

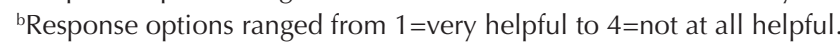

"The "End Basic Science Evaluation Index" was computed by averaging responses to the four basic science evaluation items.

'The "End Dental Topic Evaluation Index" was computed by averaging responses to the four dentistry-related evaluation items.

eThe "End Evaluation of Academic Skills Education Index" was computed by averaging responses to the four academic skills-related items.

'The "End Organizational Index" was computed by averaging responses to the five organizational items. 
from $1=$ very to $4=$ not at all: 1.85 vs. $2.18 ; p<0.05$ ) at the end of the program. In addition, when asked how helpful it was to find their way around Ann Arbor, the students indicated that it was very helpful.

Table 5 provides an overview of correlations between responses at the beginning and end of the program. The more interested students were to participate at the beginning, the more interested they were in learning about the basic sciences, dental subjects, and academic issues and the more confident they were in learning about dental topics. There was also a significant correlation between the students' beginning confidence in doing well in basic sciences and their confidence in doing well in dental-related subjects $(\mathrm{r}=0.54 ; \mathrm{p}<0.001)$.

Looking at the correlations between indices at the end of the program, we found significant correlations between considering it was worth their time and the average ratings on the perceived helpfulness of learning about basic sciences, dental-related subjects, academic skills education, and organizational/ nonacademic topics. These significant relationships indicated that all components of the program were helpful in making it beneficial.
However, when information from the beginning of the program was compared with responses at the end, the data showed that overall beginning interest in participating in the program was only correlated with evaluation of organizational skills in the end survey. An interest in dental issues at the beginning of the program was correlated with evaluating the orientation as being worthwhile at the end and with the end evaluations of how helpful it was to learn about academic skills and organizational issues.

We also explored relationships between two structural variables: year in which students participated and number of participants in the program (Table 6). The more recently students had participated, the less confident they were at the beginning about their basic science abilities $(r=-0.17 ; \mathrm{p}<0.01)$, the more worthwhile they thought the program had been at the end $(r=0.37 ; p<0.001)$, and the more positively they evaluated the program content at the end. The more participants the program had, the more confident they were in their basic science and dental-related skills at the beginning, and the more positive they evaluated the basic and dental-related science content at the end.

Table 5. Correlations between interest- and confidence-related responses at beginning of program and evaluations of program components at end of program

\begin{tabular}{|c|c|c|c|c|c|c|c|c|c|c|}
\hline \multirow[b]{2}{*}{ Item/Index } & \multicolumn{5}{|c|}{ Beginning Responses on Item/Index } & \multicolumn{5}{|c|}{ End Responses on Item/Index } \\
\hline & B & $\mathrm{C}$ & $\mathrm{D}$ & E & $\mathrm{F}$ & G & $\mathrm{H}$ & I & $J$ & K \\
\hline \multicolumn{11}{|l|}{ Beginning of program } \\
\hline $\begin{array}{l}\text { A. I am very interested in } \\
\text { participating }\end{array}$ & $0.33^{* * *}$ & $0.27^{* * *}$ & $0.20^{* * *}$ & 0.12 & $0.15^{*}$ & 0.02 & -0.08 & -0.20 & -0.11 & $-0.17^{*}$ \\
\hline B. Interest in basic science ${ }^{b}$ & & $0.25^{* * *}$ & 0.10 & -0.03 & 0.09 & 0.01 & -0.08 & -0.13 & -0.08 & -0.05 \\
\hline C. Interest in dental issues ${ }^{b}$ & $0.25^{* * *}$ & & 0.05 & $0.23 * * *$ & 0.04 & $0.20 * *$ & 0.04 & -0.17 & $-0.17^{*}$ & $-0.21^{* *}$ \\
\hline D. Interest in academic skills ${ }^{b}$ & 0.10 & 0.05 & & 0.06 & 0.04 & -0.05 & -0.18 & -0.02 & $-0.22 * *$ & -0.06 \\
\hline E. Confidence in basic science ${ }^{b}$ & -0.03 & $0.23^{* * *}$ & 0.06 & & $0.54^{* * *}$ & 0.08 & -0.03 & -0.10 & $-0.16^{*}$ & -0.02 \\
\hline F. Confidence in dental topics ${ }^{b}$ & 0.09 & 0.04 & 0.06 & $0.54^{* * *}$ & & -0.07 & -0.10 & 0.09 & -0.11 & 0.02 \\
\hline \multicolumn{11}{|l|}{ End of program } \\
\hline $\begin{array}{l}\text { G. Was this program worth } \\
\text { your time? }\end{array}$ & 0.01 & $0.20^{* *}$ & -0.05 & -0.07 & -0.07 & & $-0.78^{* * *}$ & $-0.82^{* * *}$ & $-0.49^{* * *}$ & $-0.73^{* * *}$ \\
\hline H. Basic science education ${ }^{d}$ & -0.08 & 0.04 & -0.18 & -0.03 & -0.10 & $-0.78^{* * *}$ & & $0.87^{* * *}$ & $0.63^{* * *}$ & $0.76^{* * *}$ \\
\hline I. Dental topic education ${ }^{\mathrm{d}}$ & -0.13 & -0.17 & -0.02 & -0.10 & 0.09 & $-0.82^{* * *}$ & $0.87^{* * *}$ & & $0.60^{* * *}$ & $0.78^{* * *}$ \\
\hline J. Academic skills education ${ }^{d}$ & -0.08 & $-0.17^{*}$ & $-0.22 * *$ & $-0.16^{*}$ & -0.11 & $-0.49^{* * *}$ & $0.63^{* * *}$ & $0.60^{* * *}$ & & $0.66^{* * *}$ \\
\hline K. Organizational information ${ }^{d}$ & -0.05 & $-0.21^{* *}$ & -0.06 & 0.02 & 0.02 & $0.73^{* * *}$ & $0.76^{* * *}$ & $0.78^{* * *}$ & $0.66^{* * *}$ & \\
\hline
\end{tabular}

Note: Letters in column headings refer to item/index defined for each row; so, for example, B is "Interest in basic science." See Table 3 notes for how "Beginning Basic Science Interest Index" (B), "Beginning Dental Interest Index" (C), "Academic Skill Interest" (D), "Beginning Basic Science Confidence Index" (E), and "Beginning Dental-Related Confidence Index" (F) were computed. See Table 4 notes for how "End Basic Science Evaluation Index" $(\mathrm{H})$, "End Dental Topic Evaluation Index" (I), "End Evaluation of Academic Skills Education Index" (J), and "End Organizational Index" (K) were computed.

${ }^{*} \mathrm{p}<0.05 ;{ }^{* *} \mathrm{p}<0.01 ;{ }^{* * *} \mathrm{p}<0.001$

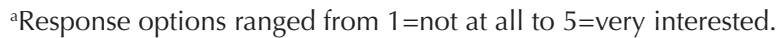

${ }^{\text {b }}$ Response options ranged from $0=$ not at all to $4=$ very interested/confident.

cResponse options ranged from $1=$ not at all worthwhile to $5=$ very worthwhile.

${ }^{\mathrm{d}}$ Response options ranged from $1=$ very helpful to $4=$ not at all helpful. 
Table 6. Correlations between beginning and end of program responses and year of program and number of participants

\begin{tabular}{|c|c|c|}
\hline Item/Index & Year & Number of Partic \\
\hline \multicolumn{3}{|l|}{ Beginning of program } \\
\hline A. I am very interested in participating in this programa & 0.07 & 0.04 \\
\hline B. Interest in basic science ${ }^{a}$ & 0.06 & 0.09 \\
\hline C. Interest in dental issues ${ }^{a}$ & 0.00 & 0.06 \\
\hline D. Interest in academic skills ${ }^{b}$ & 0.05 & 0.01 \\
\hline E. Confidence in basic science ${ }^{a}$ & $-0.17^{* *}$ & $0.17^{* *}$ \\
\hline F. Confidence in dental topics ${ }^{a}$ & -0.03 & $0.13^{*}$ \\
\hline \multicolumn{3}{|l|}{ End of program } \\
\hline G. Was this orientation worth your time?c & $0.37 * * *$ & -0.03 \\
\hline H. Evaluation of basic science ${ }^{d}$ & $-0.48^{* * *}$ & $-0.65^{* * *}$ \\
\hline I. Evaluation of dental topic education ${ }^{\mathrm{d}}$ & $-0.59 * * *$ & $-0.27^{* *}$ \\
\hline J. Evaluation of academic skills education ${ }^{d}$ & $-0.28^{* * *}$ & -0.08 \\
\hline K. Evaluation of organizational information ${ }^{d}$ & $-0.45^{* * *}$ & 0.09 \\
\hline
\end{tabular}

Note: See Table 3 notes for description of indices B to F and Table 4 notes for description of indices $\mathrm{H}$ to $\mathrm{K}$.

aResponse options ranged from $1=$ not at all interested/confident to $5=$ very interested/confident.

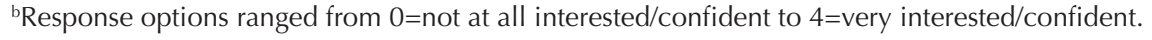

'Response options ranged from $1=$ not at all worthwhile to $5=$ very worthwhile.

${ }^{\mathrm{d}}$ Response options ranged from $1=$ very helpful to $4=$ not at all helpful.

${ }^{*} \mathrm{p}<0.05 ;{ }^{* *} \mathrm{p}<0.01 ;{ }^{* * *} \mathrm{p}<0.001$

\section{Discussion}

A more holistic approach to the selection of students for dental school allows schools to select future dentists from diverse ethnic/racial groups and socioeconomic backgrounds and students with positive service orientations, a sense of civic responsibility, and an ability to work in teams, ${ }^{2,9-11}$ as well as those motivated to provide the best possible care to an increasingly diverse patient population. However, increasing the number of students with these characteristics may result in higher numbers of students from non-traditional backgrounds such as college majors in the humanities or social sciences or with years of employment between college graduation and enrollment in dental school. Offering an academic pre-orientation program to these students will hopefully help them to start their dental education with a better understanding of the rigorous demands of the dental curriculum and an opportunity to make informal connections with faculty and with students not only in their own cohort but in upper classes. Efforts to create a social support network may help students from nontraditional backgrounds cope well with the high demands of the very rigorous predoctoral dental curriculum. ${ }^{13}$

Birks et al. found that dental students experienced a higher average level of stress than even medi- cal and nursing students. ${ }^{14}$ Alzahem et al. pointed to the large number of examinations dental students have to take as a source of their stress and emphasized the stress associated with clinical requirements needed for graduation and from dealing with supervisors with different personalities. ${ }^{15}$ Schmitter et al. found that this increased stress level was likely to result from "social overload, performance pressure at work, and lack of social recognition." ${ }^{16}$ One moderating factor for reducing stress levels among dental students is to have a positive social support network. ${ }^{17,18}$ Providing students from non-traditional backgrounds opportunities to create such a social support network during their academic pre-orientation could therefore allow them to be better prepared to cope with the stress in dental school.

Identifying which program components potential participants might be most interested in could allow for creating programs that motivate all invited participants to attend the programs. At the beginning of the program, the majority of the attendees were "very interested" and the rest were "interested" in participating. While all students were interested in getting to know their new environment, their instructors, and other dental students, the mean interest in learning dentistry-related content was higher than the mean interest in basic science content. Academic skills-related content, especially reading skills training and learning how to manage 
stress, received the least positive evaluations at the beginning. However, previous studies of the effects of academic skills training units on students who participated in two summer enrichment programs found that they significantly increased the students' academic preparedness. ${ }^{19,20}$

At the end of the program in this study, that pattern of responses was repeated. The majority of students found it helpful to have organizational information provided and to learn about upcoming academic subjects. However, fewer students appreciated the academic skills instruction. Based on these findings, the recommendation could be made to create programs that allow incoming dental students to become familiar with the new environment and members of the dental school community and to increase dental-related content.

In times of increased use of social media and digital learning opportunities, one might expect that participation in on-site programs might become less valuable. However, this study's results showed that the more recently the participants attended the program, the more they thought at the end that it had been worth their time. The finding that the more recently they attended, the more helpful they found all program components, provides strong evidence of the persistent importance and value of such programs. These findings suggest that creating academic preorientation programs at other dental schools could be beneficial for incoming dental students from non-traditional backgrounds as well.

Concerning the number of participants that should be invited to such a program, the data demonstrated that the greater the number of participants, the more helpful the respondents considered the basic science and the dentistry-related content to be. One potential explanation for this finding could be that having more opportunities to work with others in study groups or ask questions might be perceived as beneficial. This finding deserves further investigation.

This study had several limitations. First, since the program and the study were conducted at one dental school, generalizations to programs in different settings should be made with care. The second limitation is that the invited program participants had self-selected to attend in the program, while a significant number of invited students did not choose to attend. It is therefore possible that the attendees were more likely to positively evaluate the program. Finally, despite informing the students that their responses were anonymous, it is possible that the respondents did not believe that was the case due to the small group size and might therefore have responded in a more positive manner.

\section{Conclusion}

In this study, an academic pre-orientation program for non-traditional incoming dental students was positively evaluated by program participants. At the beginning of the program, students were more interested in learning about basic science and dentistry-related topics than about academic skills and were more confident in their dentistry-related than their basic science-related abilities. At the end of the program, the participants valued basic science and dentistry-related program components more highly than academic skills training, raising the question whether academic skills training should be included in the program. The finding that confidence in doing well and interest in basic science and dentistry-related topics were correlated points to the importance of increasing students' self-confidence as a potential way of ensuring increased motivation for engaging with the curricular content. The more recently participants attended this program, the less confident they were in their basic science abilities and the more worthwhile they considered the program. The more participants the program had, the more confident the students were and the better they evaluated their basic science and dentistry-related education content, pointing to the importance of ensuring positive group dynamics in academic pre-orientation programs to allow establishing social support networks.

\section{Acknowledgments}

Between 1997 and 2012, the academic pre-orientation programs were supported by Health Careers Opportunity Program (HCOP) grants (1997-2000: \#D18MB02745-02; 2001-04: \#D18HP03112; 200407: \#D18HP 03112-01; 2009-12: D18HP136340100; Principal Investigator Dr. Marilyn Woolfolk). Funding for 2013 through 2016 was provided by the Office of Student Services through the general fund of the University of Michigan School of Dentistry.

\section{REFERENCES}

1. Flexner A. Medical education in the United States and Canada: a report to the Carnegie Foundation for the advancement of teaching. New York: Carnegie Foundation, 1910 . 
2. Steinecke A, Terrell C. Progress for whose future? The impact of the Flexner report on medical education for racial and ethnic minority physicians in the United States. Acad Med 2010;85(2):236-45.

3. Mahon KE, Henderson MK, Kirch DG. Selecting tomorrow's physicians. Acad Med 2013;88(12):1806-11.

4. Kirch DG. Transforming admissions: the gateway to medicine. JAMA 2012;308(21):2250.

5. Monroe A, Quinn E, Samuelson W, et al. An overview of the medical school admission process and use of applicant data in decision making. Acad Med 2013;88(5):672-81.

6. Stratton TD, Elam CL. A holistic review of the medical school admission process: examining correlates of academic underperformance. Med Educ 2014;19.

7. Witzburg RA, Sondheimer HM. Holistic review: shaping the medical profession one applicant at a time. N Engl J Med 2013;368(17):1565-7.

8. Scott LD, Zerwic J. Holistic review in admissions: a strategy to diversify the nursing workforce. Nurs Outlook 2015;63(4):488-95.

9. Price SS, Crout RJ, Mitchell DA, Brunson DW. Increasing minority enrollment utilizing dental admissions workshop strategies. J Dent Educ 2008;72(11):339-47.

10. Grbic D, Jones DJ, Case ST. The role of socioeconomic status in medical school admissions. Acad Med 2015;90 (7):953-60

11. Koenig TW, Parrish SK, Terregino CA, et al. U.S. core personal competencies important to entering students' success in medical school. Acad Med 2013;88(5):603-13.

12. Gurin P, Dey E, Hurtado S, Gurin G. U.S. diversity and higher education: theory and impact on educational outcomes. Harv Educ Rev 2002;72(3):330-67.
13. Crego A, Carrillo-Diaz M, Armfield JM, Romero M. Stress and academic performance in dental students: the role of coping strategies and examination-related self-efficacy. J Dent Educ 2016;80(2):165-72.

14. Birks Y, McKendree J, Watt I. Emotional intelligence and perceived stress in health care students: a multiinstitutional, multi-professional survey. BMC Med Educ 2009;9:61.

15. Alzahem AM, Van der Molen HT, Alaujan AH, De Boer BJ. Stress management in dental students: a systematic review. Adv Med Educ Pract 2014;28(5):167-76.

16. Schmitter M, Liedl M, Beck J, Rammelsberg P. Chronic stress in medical and dental education. Med Teach 2008;30(1):97-9.

17. Muirhead V, Locker D. Canadian dental students' perceptions of stress and social support. Eur J Dent Educ 2008;12(3):144-8.

18. Harrison PL, Shaddox LM, Garvan CW, Behar-Horenstein LS. Wellness among dental students: an institutional study. J Dent Educ 2016;80(9):1119-25.

19. Markel G, Woolfolk MW, Inglehart MR. Feeding the pipeline: academic skills training for pre-dental students. J Dent Educ 2008;72(6):653-61.

20. Johnson KP, Woolfolk MW, May KB, Inglehart MR. Effect of an enrichment program on DAT scores of potential dental students from disadvantaged backgrounds. J Dent Educ 2013;77(8):1065-73. 